\title{
Synthesis, crystal structure, spectroscopic study and Hirshfeld surface analysis of $\left[\mathrm{Ni}\left(\mathrm{C}_{6} \mathrm{H}_{8} \mathrm{~N}_{2}\right)_{3}\right] \mathrm{Cl}_{2} .2\left(\mathrm{H}_{2} \mathrm{O}\right)(1)$
}

\author{
W. Jbali ${ }^{1}$, W. Selmi ${ }^{1^{*} \oplus, \text { L. Jouffret }^{2}}{ }^{\oplus}$, R. Marzouki ${ }^{3}{ }_{\oplus}$, M. F. Zid $^{1}$ \\ *Email corresponding author: selmiwafa88@gmail.com
}

\begin{abstract}
${ }^{1}$ University of Tunis El Manar, Faculty of Sciences of Tunis, Laboratory of Materials, Crystal Chemistry and Applied Thermodynamics, 2092 El Manar II, Tunis, Tunisia

${ }^{2}$ Université Clermont Auvergne, 24, avenue Blaise Pascal, TSA 60026 CS 60026 ;63178 Aubière Cedex

${ }^{3}$ Chemistry Department, College of Science, King Khalid University, Abha 61413, Saudi Arabia
\end{abstract}

\begin{abstract}
The title compound, $\left[\mathrm{Ni}\left(\mathrm{C}_{6} \mathrm{H}_{8} \mathrm{~N}_{2}\right)_{3}\right] \mathrm{Cl}_{2} \cdot 2\left(\mathrm{H}_{2} \mathrm{O}\right)$, was synthesized by slow evaporation method at room temperature. The structural study by $\mathrm{X}$-ray diffraction indicate that this compound crystallize in the triclinic system, P-1 space group with $a=10.222(2) \AA, b=10.757(2) \AA$, $c=11.441(3) \AA, \alpha=114.30(4)^{\circ}, \beta=99.43(3)^{\circ}$ and $\gamma=93.01(3)^{\circ}$. The structure is formed by the cation $\left[\mathrm{Ni}\left(\mathrm{C}_{6} \mathrm{H}_{8} \mathrm{~N}_{2}\right)_{3}\right]^{2+}$, tow chloride anions and two molecules water of crystallization. The nickel (II) atom is coordinated to six nitrogen donors from three neutral 2-AMP ligands, adopting a slightly distorted octahedral geometry. The crystal structure is stabilized by strong hydrogen bonds of $\mathrm{N}-$ $\mathrm{H} . . . \mathrm{Cl}, \mathrm{O}-\mathrm{H} . . . \mathrm{Cl}, \mathrm{C}-\mathrm{H} . . . \mathrm{Cl}$ and $\pi-\pi$ interactions to obtained three-dimensional network. The newly prepared compound was characterized by XRD, Infrared, UV-Vis spectroscopy and Hirshfeld surface (3D-HS) analysis. Vibrational analysis of the compound was realized by infrared spectroscopy. The optical properties of the crystal were studied using optical absorption UVvisible spectroscopy which confirmed the semiconducting properties by revealing a direct optical band. Hirshfeld Surface projections and Fingerprint plots were elucidated the relative contribution of the $\mathrm{H} \ldots \mathrm{Cl}, \mathrm{C} \ldots \mathrm{H}, \mathrm{C} \ldots \mathrm{C}, \mathrm{C} \ldots \mathrm{N}, \mathrm{H} \ldots \mathrm{O}$ intermolecular contacts in the crystal.
\end{abstract}

\section{Keywords}

Nickel (II) organic-inorganic materials; Crystal structure; Hirshfeld surface; XRD; Hydrogen bonds. 


\section{Introduction}

Crystal engineering in recent years is the most area of research developed, which study the new solids materials establish by the intermolecular attractions with specific structural topology design and applications [1].The surge in the field of supramolecular chemistry is due to the several capacities which offered in the fields of biological and materials sciences. The easy manipulation of their assemblage process and prospective applications has been involved tremendous attention to supramolecular systems for many years, not only in the field of chemistry but also physics, materials and biological sciences, making this field a true interdisciplinary domain of research [2]. Complexation of transition metals with 2-(aminomethyl)pyridine (2-AMP) in aqueous solutions has been extensively studied [3]. As a ligand the tow amino-methyl-pyridines can function as bridging as well as chelating [4]. Recently much more attention has been paid to the study of complexes formed by 2-aminopyridine with metal ions which have good magnetic properties, biological activity, and structural diversity. These complexes can serve as pro-drugs such as antitumor, antibacterial and anticancer agents [5]. The bi-functional organic amine 2-aminomethylpyridine include a pyridine ring and an aliphatic amine group is an excellent choice as an organicinorganic synthesis model. It is used in large-scale industrial applications [6], it is also used for analytical chemistry and medical detection [7]. In addition, some metal-pyridine coordination compounds have been explored for the design of novel nonlinear optical materials [8].

In our paper, we report the synthesis of new coordination compound of nickel(II) with 2-AMP. The structure $\left[\mathrm{Ni}\left(\mathrm{C}_{6} \mathrm{H}_{8} \mathrm{~N}_{2}\right)_{3}\right] \mathrm{Cl}_{2} .2\left(\mathrm{H}_{2} \mathrm{O}\right)$ was determined by X-ray diffraction, identified by IR

spectroscopy and the Tauc plot method was also applied to determine the optical band gap from $\mathrm{UV}-\mathrm{V}$ is diffuse reflectance spectroscopy. The intermolecular contacts in the crystal were investigated by Hirshfeld surface (3D-HS) analysis.

\section{Experimental}

\subsection{Materials and measurements}

All reagents and solvents were obtained from commercial sources and used without further purification, 2-(aminomethyl)pyridine (2-AMP) was obtained from Aldrich chemical. To gain more information on the crystal structure, a vibrational study was undertaken. The absorption spectroscopy FT-IR was measured in the $500-4000 \mathrm{~cm}^{-1}$ range, by $\mathrm{KBr}$ pellet technique on a Bruker FT-IR spectrophotometer. The UV-visible spectrum of title compound was measured with 
Ellice SLe164 Double BEAM at room temperature in the range from 200 to $800 \mathrm{~nm}$. The sample was measured with the PANalytical Empyrean powder diffractometer equipped with a focusing mirror and a PIXCel3D detector.

\subsection{Synthesis of $\left[\mathrm{Ni}\left(\mathrm{C}_{6} \mathrm{H}_{8} \mathrm{~N}_{2}\right)_{3}\right] \mathrm{Cl}_{2} .2 \mathrm{H}_{2} \mathrm{O}$}

The coordination compound $\left[\mathrm{Ni}\left(\mathrm{C}_{6} \mathrm{H}_{8} \mathrm{~N}_{2}\right)_{3}\right] \mathrm{Cl}_{2} .2 \mathrm{H}_{2} \mathrm{O}$ was prepared by mixing nickel(II) chloride hexahydrate $\left(\mathrm{NiCl}_{2} .6 \mathrm{H}_{2} \mathrm{O}\right)(0.237 \mathrm{~g})$ and 2-amino-methylpyridine $\left(\mathrm{C}_{6} \mathrm{H}_{8} \mathrm{~N}_{2}\right)(1.049 \mathrm{~g} / \mathrm{mL})$ (purity $99 \%$ ) in water. The resulting solution was well stirred than kept at room temperature. After three weeks, pink-violet crystals were formed. The slow evaporation allows the obtention of very highquality crystals of $\left[\mathrm{Ni}\left(\mathrm{C}_{6} \mathrm{H}_{8} \mathrm{~N}_{2}\right)_{3}\right] \mathrm{Cl}_{2} \cdot 2 \mathrm{H}_{2} \mathrm{O}$. A single crystal suitable for $\mathrm{X}$-ray diffraction analysis was selected and studied. The elemental analysis for $\left[\mathrm{Ni}\left(\mathrm{C}_{6} \mathrm{H}_{8} \mathrm{~N}_{2}\right)_{3}\right] \mathrm{Cl}_{2} \cdot 2 \mathrm{H}_{2} \mathrm{O}$ is : \% $=44.12$, $\% \mathrm{H}=5.76, \% \mathrm{~N}=17.15, \% \mathrm{Cl}=14.47, \% \mathrm{O}=6.53, \% \mathrm{Ni}=11.98$.

\subsection{Crystallographic studies}

A crystal of size $\left(0.56 \times 0.490 .28 \mathrm{~mm}^{3}\right)$ was selected for the structural analysis diffraction data which collected at $298 \mathrm{~K}$ with Enraf-Nonius CAD4 automatic four-circle equipped with graphite monochromator using Mo K $\alpha$ radiation $(\lambda=0.71073 \AA$ ) [9].

The hydrogen atoms bonded to the carbon atoms of the aromatic ring were placed by geometric

calculation, $\mathrm{C}-\mathrm{H}=0.93 \AA, \mathrm{N}-\mathrm{H}=0.85 \AA$. At this stage, an absorption correction by psi-scan [10] was performed $\left(\mathrm{T}_{\min }=0.882, \mathrm{~T}_{\max }=1.000\right)$. In addition, the refinement of the anisotropic parameters leads to confidence factors of the order of $\mathrm{R}\left(\mathrm{F}^{2}\right)=4 \%$ and $\mathrm{wR}\left(\mathrm{F}^{2}\right)=11.2 \%$.

The results of the crystallographic data, the data collection conditions and the refinement of the $\left[\mathrm{Ni}\left(\mathrm{C}_{6} \mathrm{H}_{8} \mathrm{~N}_{2}\right)_{3}\right] \mathrm{Cl}_{2} .2 \mathrm{H}_{2} \mathrm{O}$ structure are presented in Table 1.

The graphical illustrations of the structure were made using the CIF file, using the Diamond 3.0 program [11].

CIF file having complete information about the structure of dichlorotris(2aminomethylpyridine)nickel(II) dihydrate, was deposited in the Cambridge Crystallographic Data Center (1896844). The file is freely available upon request from the following web site: http://www.ccdc.cam.ac.uk/data_request/cif. 
Table 1. Crystallographic and structure refinement data of $\left[\mathrm{Ni}\left(\mathrm{C}_{6} \mathrm{H}_{8} \mathrm{~N}_{2}\right)_{3}\right] \mathrm{Cl}_{2} \cdot 2 \mathrm{H}_{2} \mathrm{O}$

\begin{tabular}{|c|c|}
\hline \multicolumn{2}{|l|}{ Crystal data } \\
\hline Empirical formula & {$\left[\mathrm{Ni}\left(\mathrm{C}_{6} \mathrm{H}_{8} \mathrm{~N}_{2}\right)_{3}\right] \mathrm{Cl}_{2} \cdot 2 \mathrm{H}_{2} \mathrm{O}$} \\
\hline Formula weight $\left(\mathrm{g} \mathrm{mol}^{-1}\right)$ & 490.07 \\
\hline Temperature (K) & 293 \\
\hline Crystal system & Triclinic \\
\hline Space group & $\mathrm{P}-1$ \\
\hline $\begin{array}{l}\mathrm{a}(\AA), \alpha\left(^{\circ}\right) \\
\mathrm{b}(\AA), \beta\left(^{\circ}\right) \\
\mathrm{c}(\AA), \gamma\left(^{\circ}\right)\end{array}$ & $\begin{array}{l}10.222(2), 114.30(4) \\
10.757(2), 99.43(3) \\
11.441(3), 93.01(3)\end{array}$ \\
\hline $\mathrm{V}\left(\AA^{3}\right)$ & $1121.1(5)$ \\
\hline $\bar{Z}$ & 2 \\
\hline $\mathrm{F}(000)$ & 512 \\
\hline Density calculated $\left(\mathrm{Mg} \mathrm{m}^{-3}\right)$ & 1.452 \\
\hline Absorption coefficient $\left(\mathrm{mm}^{-1}\right)$ & 1.13 \\
\hline Independent parameters & 376 \\
\hline Range for data collection Reflections collected Independent & $\theta_{\min }=2.0^{\circ}, \theta_{\max }=29.0^{\circ}$ \\
\hline Reflections collected-Independent & 6638- 5948 \\
\hline Rint & 0.021 \\
\hline $\mathrm{R}\left[\mathrm{F}^{2}>2 \sigma\left(\mathrm{F}^{2}\right)\right]$ & 0.035 \\
\hline $\mathrm{wR}\left(\mathrm{F}^{2}\right)$ & 0.094 \\
\hline S (GOOF) & 1.02 \\
\hline
\end{tabular}

\subsection{Hirshfeld surface analysis}

Analysis of intermolecular interactions via Hirshfeld Surface-based tools is a major advance in enabling supramolecular chemist to clarify the intermolecular interactions and to understand the role of the organic base in structural propagation. The Hirshfeld surfaces [12] and their relative 2D fingerprint plots [13] were drawn using CrystalExplorer 3.1 [14]. The quantifying and decoding of the intermolecular contacts in the crystal packing are visualized using $\mathrm{d}_{\text {norm }}$ (normalized contact distance) and 2D fingerprint plots were $d_{i}$ (inside) and $d_{e}$ (outside) represent the distances to the Hirshfeld surface from the nuclei, with respect to the relative van der Waals radii. The $\mathrm{d}_{\text {norm }}$ values were mapped into the Hirshfeld surface using a red; white, blue color scheme as follows: closer contacts and the negative $d_{\text {norm }}$ value represents the red regions; contacts around the van der Waals 
separation represents the white areas, the longer contacts and the positive $d_{\text {norm }}$ value represents the blue regions.

\section{Results and discussion}

\subsection{Description of the structure}

The crystalline structure of dichlorotris(2-aminomethylpyridine)nickel(II) dihydrate reveals the presence of cation complex $\left[\mathrm{Ni}\left(\mathrm{C}_{6} \mathrm{H}_{8} \mathrm{~N}_{2}\right)_{3}\right]^{2+}$, two chloride anion and two molecules water of crystallization. The constituents of the asymmetric unit are shown in the Fig. 1.

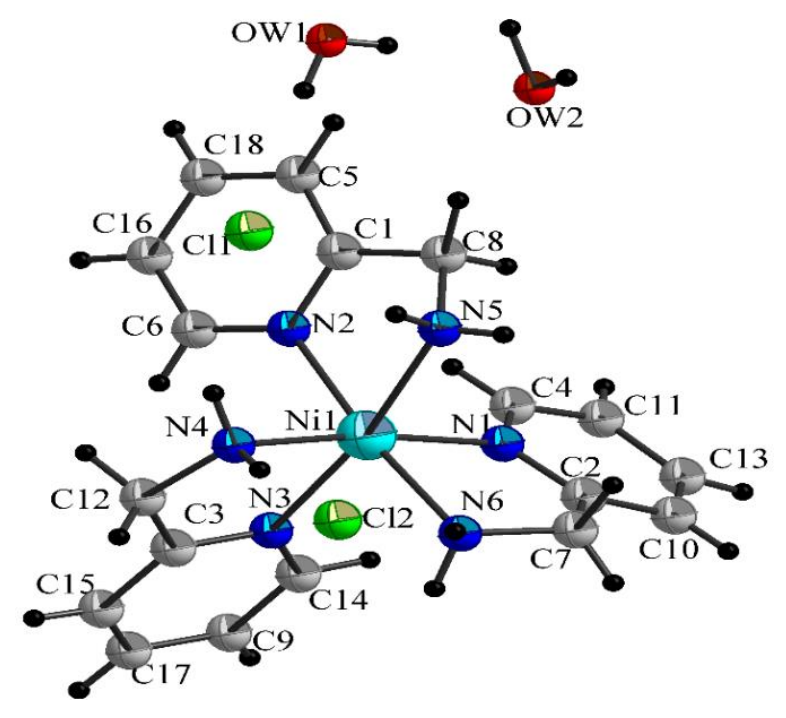

Fig. 1. The asymmetric unit of $\left[\mathrm{Ni}\left(\mathrm{C}_{6} \mathrm{H}_{8} \mathrm{~N}_{2}\right)_{3}\right] \mathrm{Cl}_{2} \cdot 2 \mathrm{H}_{2} \mathrm{O}$.

The Ni(II) ion chelated by the 2-aminomethyl-pyridine ligand (2-AMP), the octahedral geometry is completed by three equivalents of the AMP base. Ni(II) deviates from the plane defined by six nitrogen atoms leading to an octahedral with the Ni-N distances equal to Ni1-N1 = 2.108(17); Ni1-

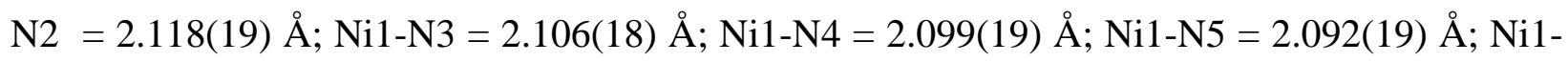
N6 = 2.109(2) A which indicate a leger distorted octahedral geometry (Table 2) which are similar to those in $\left[\mathrm{Fe}(\mathrm{py})_{4} \mathrm{Cl}_{2}\right]$, (py is pyridine) $2.229(6) \AA$ and $2.257(4) \AA$ but are slightly longer than found in literature [16]. The bite angle N1-Ni-N6 is equal to $79.610 \AA$, the measuring angle of N2Ni-N5 is $78.482 \AA$, the bite angle N3-Ni-N4 value is $80.295 \AA$, which confirms the distortion of the octahedral. A similar configuration of the $\left[\mathrm{Ni}\left(\mathrm{C}_{6} \mathrm{H}_{8} \mathrm{~N}_{2}\right)_{3}\right]^{2+}$ cation was also found in agree with the published data [15]. 
In this structure, the average values of the distortion parameters of the cation $\left[\mathrm{Ni}\left(\mathrm{C}_{6} \mathrm{H}_{8} \mathrm{~N}_{2}\right)_{3}\right]^{2+}$ are calculated using the following equations:

$$
\mathrm{ID}(\mathrm{Ni}-\mathrm{N})=1 / 6\left(\Sigma\left|d_{i}-d_{m}\right| / d_{m}\right) \quad \text { ID }(\mathrm{N}-\mathrm{Ni}-\mathrm{N})=1 / 12\left(\Sigma\left|a_{i}-a_{m}\right| / a_{m}\right)
$$

where $a_{i}$ is the $(\mathrm{N}-\mathrm{Ni}-\mathrm{N})$ angle, $d_{i}$ the $(\mathrm{Ni}-\mathrm{N})$ distance, $m$ the average values and ID $(\mathrm{Ni}-\mathrm{N})=0.0284$ and $\operatorname{ID}(\mathrm{N}-\mathrm{Ni}-\mathrm{N})=0.0164$. The values of the distortion indices indicate that the coordination geometry of the metal is slightly distorted octahedral.

Table 2. Ni-N distances and bond angles in the NiN6 octahedron

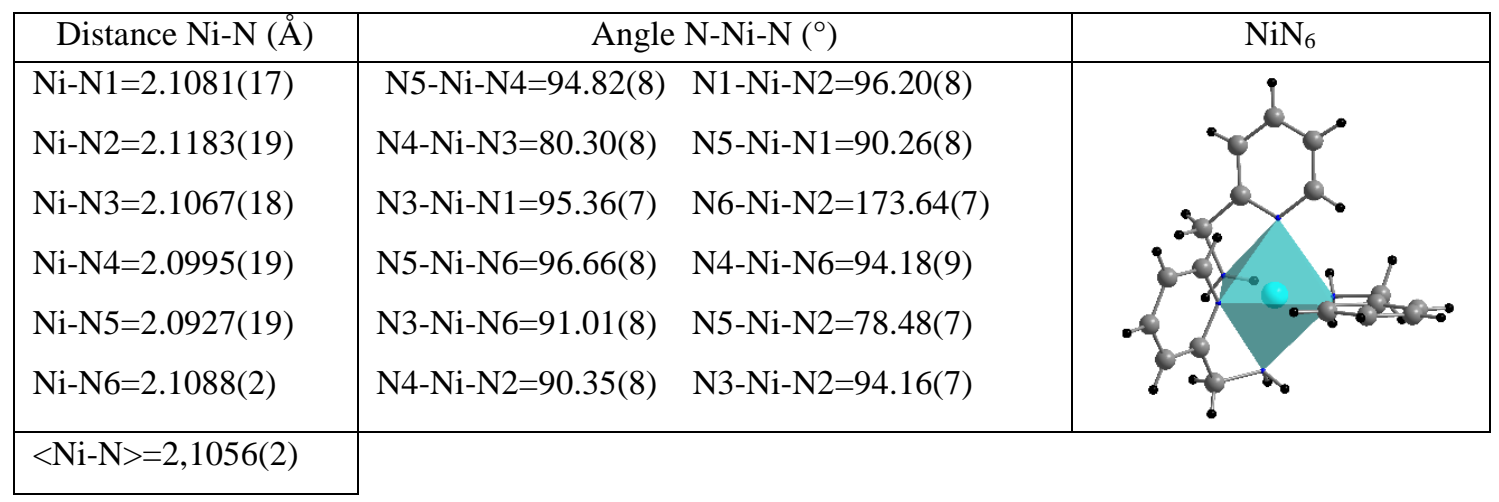

The detailed study of the hydrogen bonds of the compound $\left[\mathrm{Ni}\left(\mathrm{C}_{6} \mathrm{H}_{8} \mathrm{~N}_{2}\right)\right]_{3} \mathrm{Cl}_{2} .2\left(\mathrm{H}_{2} \mathrm{O}\right)$, has demonstrated the existence of two types of intermolecular interactions: N-H...Cl and O-H...Cl (Fig. 2.) and (Fig. 3.).

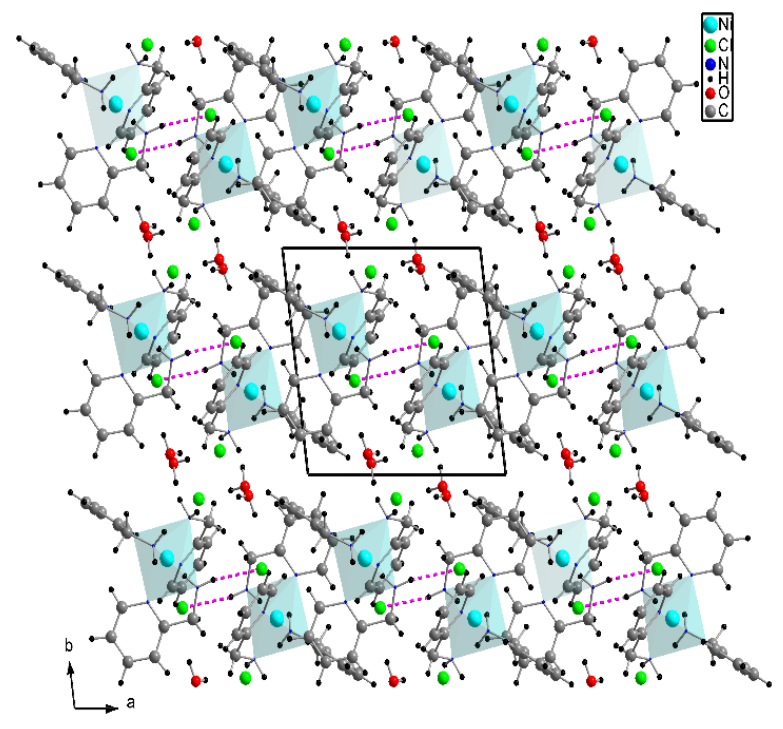

Fig. 2. N-H...Cl interactions in the (001) plane in the structure of $\left[\mathrm{Ni}\left(\mathrm{C}_{6} \mathrm{H}_{8} \mathrm{~N}_{2}\right)_{3}\right] \mathrm{Cl}_{2} .2 \mathrm{H}_{2} \mathrm{O}$.

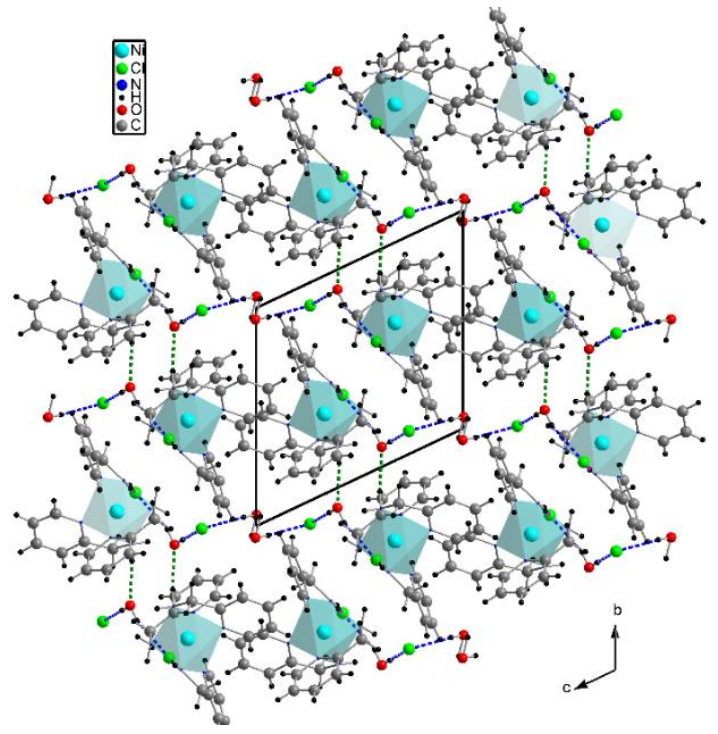

Fig. 3. O-H...Cl; N-H...O interactions in the (100) plane in the structure of $\left[\mathrm{Ni}\left(\mathrm{C}_{6} \mathrm{H}_{8} \mathrm{~N}_{2}\right)_{3}\right] \mathrm{Cl}_{2} \cdot 2 \mathrm{H}_{2} \mathrm{O}$. 
In the crystal structure, the cation complex $\left[\mathrm{Ni}\left(\mathrm{C}_{6} \mathrm{H}_{8} \mathrm{~N}_{2}\right)_{3}\right]^{2+}$, the chloride anions and the water molecules of crystallization are linked through $\mathrm{N}-\mathrm{H} . . . \mathrm{Cl}, \mathrm{N}-\mathrm{H} \ldots \mathrm{O}$ and $\mathrm{O}-\mathrm{H} . . . \mathrm{Cl}$ hydrogen bonds to form a 3D supramolecular architecture (Fig. 4).

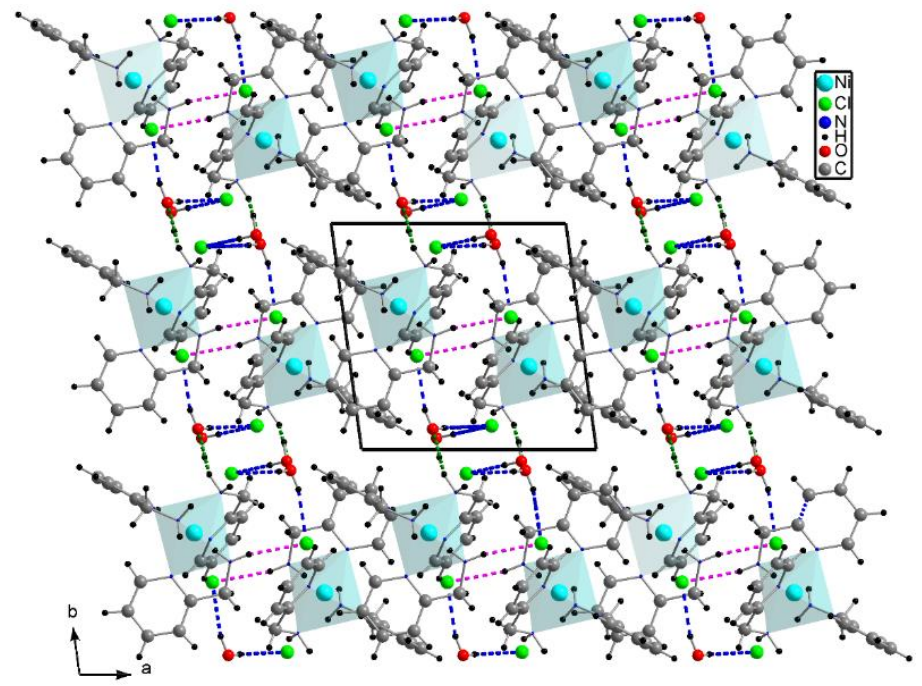

Fig. 4. 3D hydrogen-bonded supramolecular network formed by hydrogen bonding interactions (Hydrogen bonds are represented by dashed lines).

Table 3. Specified hydrogen bonds $(\AA)$ and angle $\left(^{\circ}\right)$ of $\left[\mathrm{Ni}\left(\mathrm{C}_{6} \mathrm{H}_{8} \mathrm{~N}_{2}\right)_{3}\right] \mathrm{Cl}_{2} .2 \mathrm{H}_{2} \mathrm{O}$

\begin{tabular}{|c|c|c|c|c|c|}
\hline D-H & $d(D-H)$ & $\mathrm{d}(\mathrm{H} . . \mathrm{A})$ & $<$ DHA & $\mathrm{d}(\mathrm{D} . . \mathrm{A})$ & A \\
\hline $\mathrm{C} 7-\mathrm{H} 2$ & 0.926 & 2.816 & 167.45 & 3.725 & $\mathrm{Cl} 2$ \\
\hline $\mathrm{C} 7-\mathrm{H} 4^{\mathrm{i}}$ & 0.992 & 2.837 & 167.54 & 3.811 & $\mathrm{Cl} 2$ \\
\hline N5-H5 & 0.907 & 2.428 & 154.04 & 3.267 & $\mathrm{Cl} 2$ \\
\hline C14-H6 & 0.942 & 2.662 & 122.69 & 3.268 & N1 \\
\hline $\mathrm{N} 5-\mathrm{H} 8^{\mathrm{i}}$ & 0.852 & 2.538 & 169.67 & 3.380 & $\mathrm{Cl} 1$ \\
\hline $\mathrm{C} 8-\mathrm{H} 12^{\mathrm{ii}}$ & 1.004 & 2.853 & 151.16 & 3.763 & $\mathrm{Cl} 2$ \\
\hline N6-H13 ${ }^{\text {iii }}$ & 0.859 & 2.760 & 154.95 & 3.557 & $\mathrm{Cl} 2$ \\
\hline N6-H14 & 0.900 & 2.292 & 167.79 & 3.135 & Ow1 \\
\hline $\mathrm{C} 15-\mathrm{H} 15^{\mathrm{iv}}$ & 0.942 & 2.559 & 139.36 & 3.485 & Ow1 \\
\hline $\mathrm{C} 12-\mathrm{H} 16^{\mathrm{v}}$ & 1.024 & 2.756 & 119.17 & 3.595 & $\mathrm{Cl} 1$ \\
\hline $\mathrm{C} 5-\mathrm{H} 17^{\mathrm{vi}}$ & 0.924 & 2.627 & 121.97 & 3.214 & Ow2 \\
\hline N4-H19 & $0 . .883$ & 2.748 & 153.03 & 3.557 & Cl1 \\
\hline Ow1-H23 & 0.760 & 2.481 & 166.13 & 3.224 & $\mathrm{Cl} 2$ \\
\hline Ow1-H24 vii & 0.886 & 2.437 & 166.37 & 3.304 & Cl1 \\
\hline N4-H26 viii & 0.893 & 2.427 & 172.17 & 3.315 & $\mathrm{Cl} 2$ \\
\hline Ow2-H28 & 0.846 & 2.373 & 156.83 & 3.168 & $\mathrm{Cl} 2$ \\
\hline
\end{tabular}

Symmetry codes : ${ }^{\mathrm{i}}[-\mathrm{x}+1,-\mathrm{y}+1,-\mathrm{z}+1],{ }^{\mathrm{ii}}[\mathrm{x}, \mathrm{y}+1, \mathrm{z}],{ }^{\mathrm{iii}}[-\mathrm{x}+1,-\mathrm{y},-\mathrm{z}+1],{ }^{\mathrm{iv}}[-\mathrm{x}+2,-\mathrm{y},-\mathrm{z}+1],{ }^{\mathrm{v}}[-\mathrm{x}+2,-\mathrm{y}+1,-\mathrm{z}+1]$, ${ }^{\text {vi }}[-\mathrm{x}+1,-\mathrm{y}+1,-\mathrm{z}+2],{ }^{\mathrm{vii}}[\mathrm{x}, \mathrm{y}-1, \mathrm{z}],{ }^{\text {viii }}[-\mathrm{x}+1,-\mathrm{y},-\mathrm{z}+1]$. 
As it shown clearly from Fig. 5, the two neighboring anti-parallel organic cations are linked together through the aromatic-aromatic interactions with $3.930 \AA$ distance between two pyridine rings and piled each other by turns in face to face. The two adjacent cationic dimers $\left[\mathrm{Ni}\left(\mathrm{C}_{6} \mathrm{H}_{8} \mathrm{~N}_{2}\right)_{3}\right]^{2+}$, ensure the cohesion of the crystal structure in the sub-network by the $\pi-\pi$ interactions between the aromatic rings.

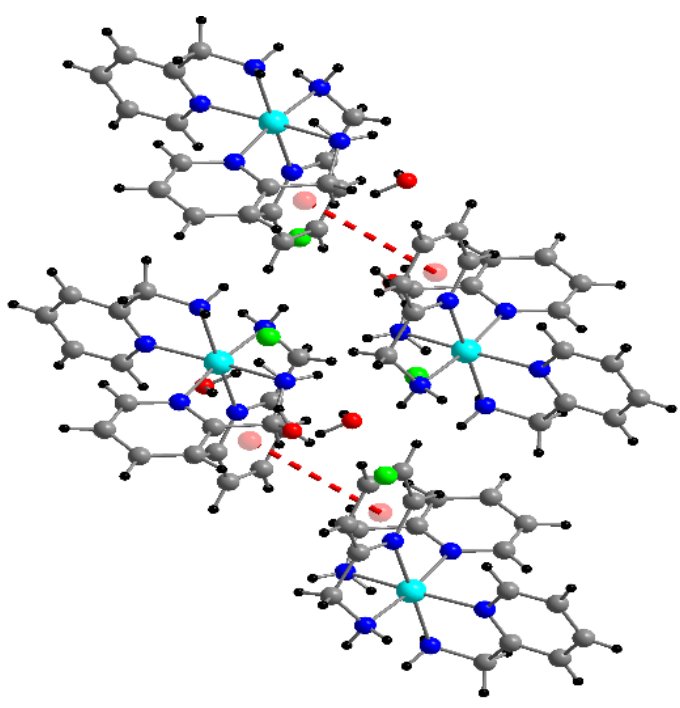

Fig. 5. The cycle stacking interaction.

\subsection{The experimental XRPD pattern}

The XRPD pattern of the compound have been analyzed to confirm the homogeneity of the synthesized material and the result was correlated with the powder pattern obtained from the single crystal XRD data simulation Fig. 6. The experimental XRPD pattern corroborate well with the corresponding powder pattern simulated from single crystal data and prove the purity phase of the bulk product. Phase purity was further confirmed by comparing the unit cell parameter obtained from single crystal XRD data and the same calculated from XRPD data.

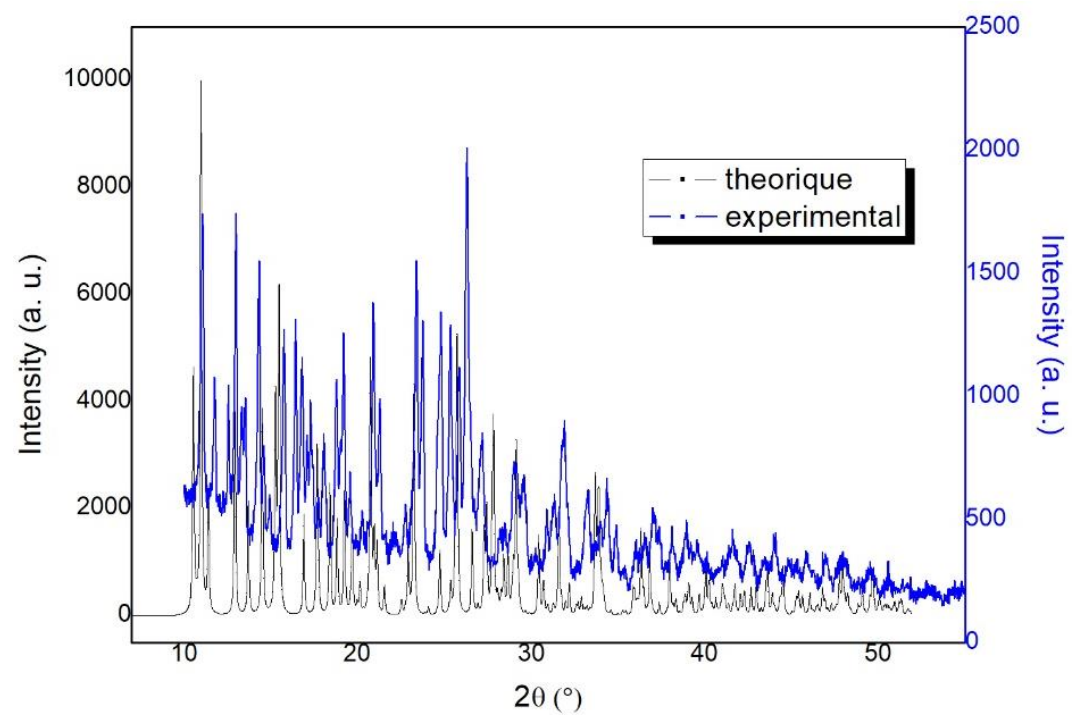

Fig. 6. Experimental and calculated diffractograms of $\left[\mathrm{Ni}\left(\mathrm{C}_{6} \mathrm{H}_{8} \mathrm{~N}_{2}\right)_{3}\right] \mathrm{Cl}_{2} .2 \mathrm{H}_{2} \mathrm{O}$. 


\subsection{Hirshfeld surface calculations}

In addition to the structural investigation of the title compound, the Hirshfeld Surfaces has been illustrated. The 3D-HS surface of the studied complex is showed in Fig. 7. The volume of contact surface is equal to $552.14 \AA^{3}$, with a contact area of $450.87 \AA^{2}$.

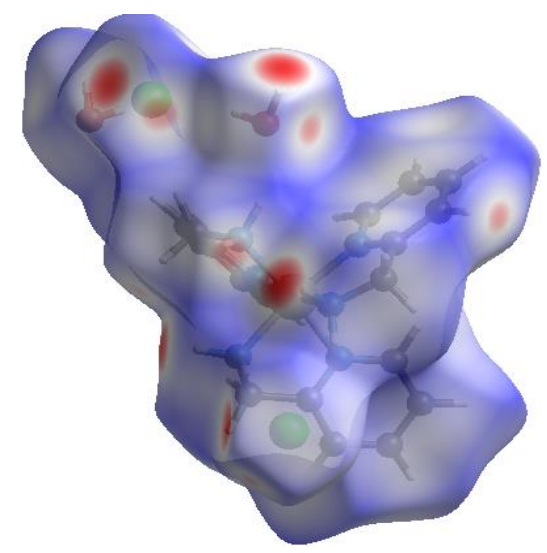

Fig. 7. 3D Hirshfeld surface mapped over $d_{\text {norm }}$ for visualizing the molecular interactions of the studied complex. The surface is shown as transparent to allow visualization of the orientation and conformation of the functional groups.

The large and deep black spots on the $d_{\text {norm }} 3 \mathrm{D}-\mathrm{HS}$ indicate the $\mathrm{O} \ldots \mathrm{H} / \mathrm{H} \ldots \mathrm{O}$ and $\mathrm{N} \ldots \mathrm{H} / \mathrm{H} \ldots \mathrm{N}$ close contacts interactions, which are mainly responsible for the significant $\mathrm{O}-\mathrm{H} \ldots \mathrm{Cl}, \mathrm{N}-\mathrm{H} \ldots \mathrm{O}$ and $\mathrm{N}-\mathrm{H} . . . \mathrm{Cl}$ hydrogen bonding interactions, respectively.

The two-dimensional fingerprint plots (2D-FP) showing the distinct kinds of intermolecular contacts are represented in Figure 8. The 2D-FP of Cl...H/H...Cl (21.1\%) (Fig. 8a) and the $\mathrm{O} \ldots \mathrm{H} / \mathrm{H} \ldots \mathrm{O}$ contacts have contributed in the 2D-FP with a minor percentage equal to $7.4 \%$ (Fig. 8b). The C ...H/H...C (14.8\%) (Fig. 8c) contact appear as a symmetric spike form which confirms the presences of $\pi-\pi$ interactions equal to $3.930 \AA$. As well, the H...H contacts appear in the middle of the scattered points in the 2D-FP with $54.9 \%$ of the total surface (Fig. 8d). This higher percentage of contribution is due to the higher proportion of hydrogen in the aromatic Ligand and the easy interactions between hydrogens atoms of the aminomethylpyridine of one molecule with the neighboring molecule. The results discussed above have the most significant contribution to the total Hirshfeld surface, but the analysis shows the existence of other weak intermolecular contacts which contributes to the vander vals interactions. 

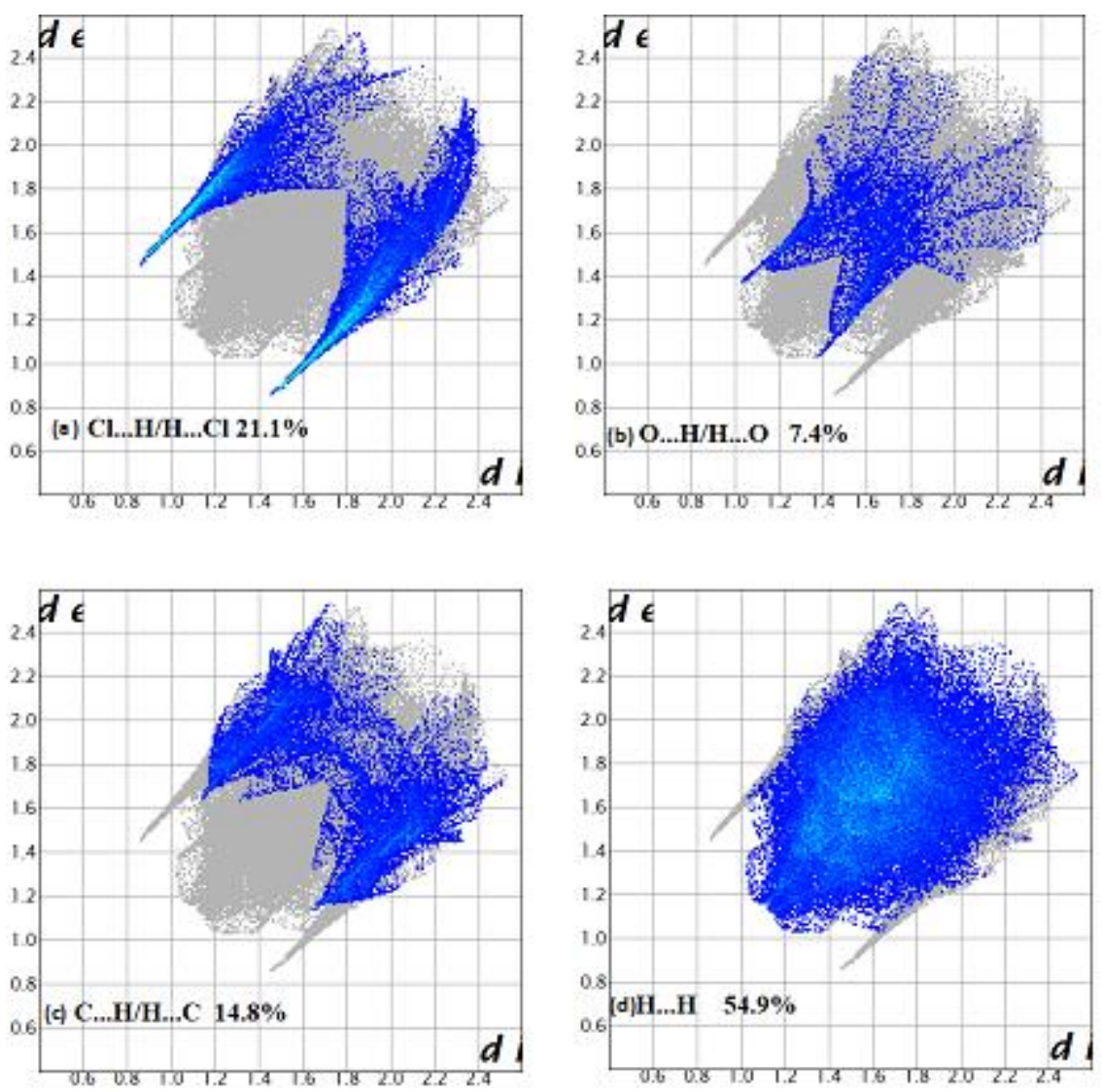

Fig. 8. 2D Fingerprint plots of the studied complex resolved into $\mathrm{Cl} \ldots \mathrm{H} / \mathrm{H} \ldots \mathrm{Cl}$ (a), $\mathrm{C} \ldots \mathrm{H} / \mathrm{H} \ldots \mathrm{C}(\mathrm{b}), \mathrm{H} \ldots \mathrm{H}(\mathrm{c})$, and $\mathrm{O} \ldots \mathrm{H} / \mathrm{H} \ldots \mathrm{O}(\mathrm{d})$ contacts showing the percentages participations to the total Hirshfeld surface area.

The void surface is reported by Crystal Explorer, in the crystal structure of dichloridetris(2aminomethylpyridine)nickel(II) dihydrate the void surface is based on the sum of spherical atomic electron densities at the appropriate nuclear positions [15].The crystal-void calculation (results under 0.002 a.u. isovalue) shows the void volume of title compound which is equal to $120.26 \mathrm{~A}^{\circ 3}$ and surface area in the order of $404.92 \mathrm{~A}^{\circ 2}$. The calculated porosity of $10.72 \%$ confirms that the cavities are not large. The electron-density isosurfaces are not completely closed around the components but are open at those locations where interspecies approaches are found, e.g. OH...Cl. 


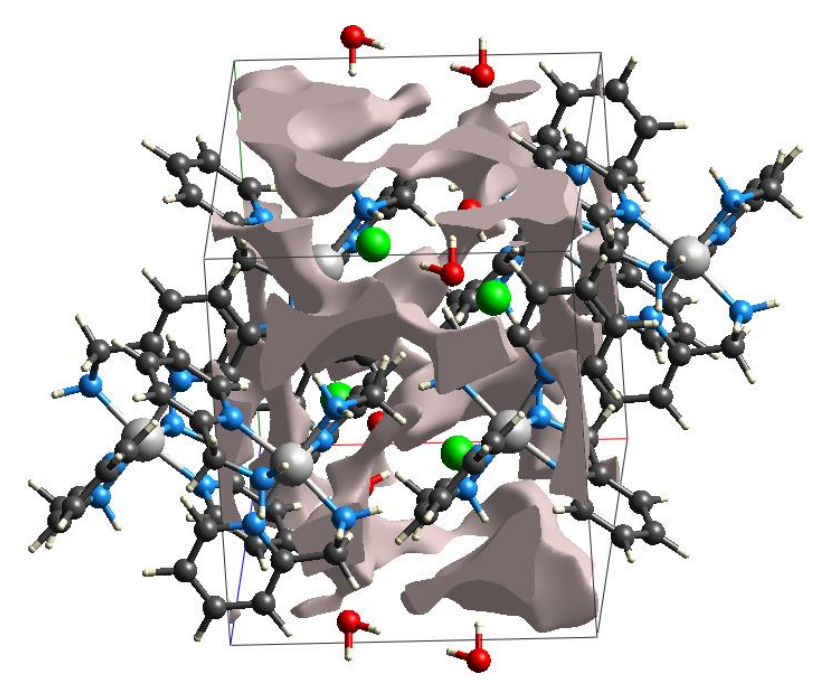

Fig. 9. The voids in the crystal structure of dichlorotris(2-aminomethylpyridine)nickel(II) dihydrate.

\subsection{Spectroscopy IR}

Infrared Spectroscopy technique was used to identify the functional groups of the crystal structure. The infrared absorption spectrum of $\left[\mathrm{Ni}\left(\mathrm{C}_{6} \mathrm{H}_{8} \mathrm{~N}_{2}\right)_{3}\right] \mathrm{Cl}_{2} \cdot 2\left(\mathrm{H}_{2} \mathrm{O}\right)$ is shown in Fig. 10. In the IR spectrum intense absorption band of water-crystallization molecule is observed between 3420 and $3640 \mathrm{~cm}^{-1}$. The typical stretching vibrations of $\mathrm{NH}_{2}, \mathrm{NH}$, and $\mathrm{CH}_{2}$ are located between 2900 and $3300 \mathrm{~cm}^{-1}$. The asymmetric and symmetric stretching mode of $\mathrm{NH}_{2}$ are found as very weak bands located respectively at 3326 and $3208 \mathrm{~cm}^{-1}$. The elongation modes $v(C=C), v(C=N), v(C-C)$ and $v(\mathrm{C}-\mathrm{N})$ of the organic unit are observed in the region of $1610-1171 \mathrm{~cm}^{-1}$. The bands at 1290,980 , $880,730,500$ and $465 \mathrm{~cm}^{-1}$ are related to the vibration in the plane and out of the plane of elongation of $\mathrm{C}=\mathrm{N}-\mathrm{C}, \mathrm{C}=\mathrm{C}-\mathrm{C}$ and $\mathrm{C}-\mathrm{C}=\mathrm{N}$. The bands detected at 1303 and $1241 \mathrm{~cm}^{-1}$ in the infrared spectrum are attributed to the stretching modes of the $\mathrm{C}-\mathrm{NH}_{2}$ bonds. The $\mathrm{Ni}-\mathrm{N}$ stretching vibration is found at $620 \mathrm{~cm}^{-1}$. These assigned absorption bands in the infrared spectrum of nickel complex are in agreement with previous complexes in the literature $[3,4]$. 


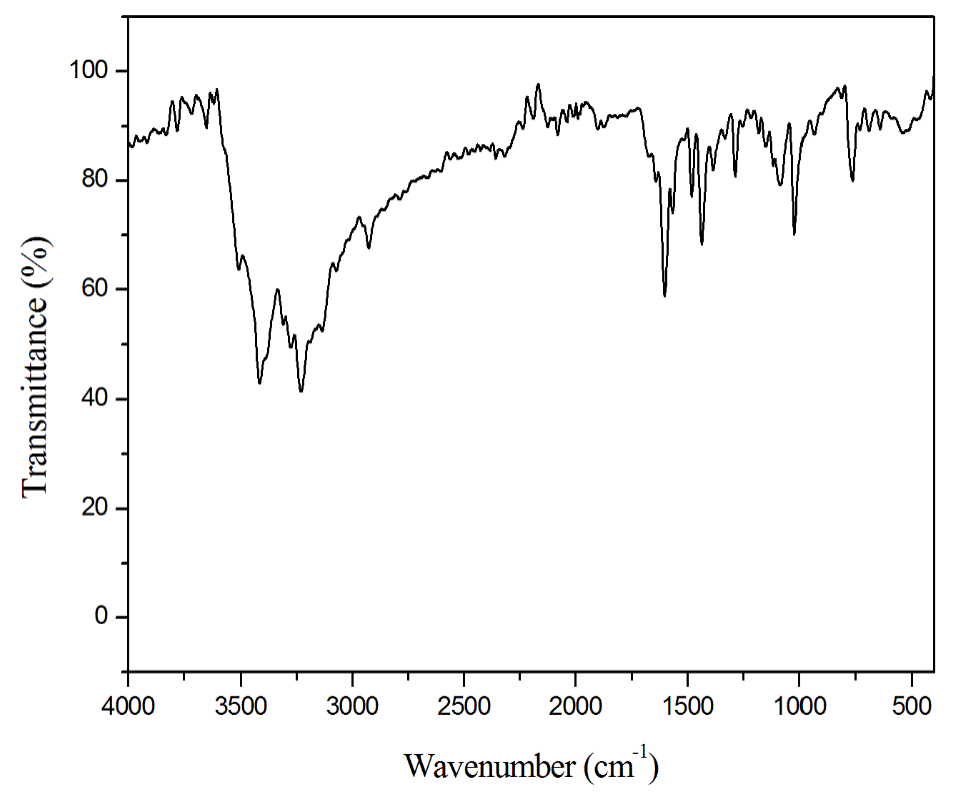

Fig. 10. Infrared spectrum of the $\left[\mathrm{Ni}\left(\mathrm{C}_{6} \mathrm{H}_{8} \mathrm{~N}_{2}\right)_{3}\right] \mathrm{Cl}_{2} .2\left(\mathrm{H}_{2} \mathrm{O}\right)$ complex.

\subsection{Optical properties}

The optical properties were studied by measuring the diffuse reflectance. The UV-vis spectrum is realized on solid-state sample at room temperature (Fig. 11). The absorption spectrum of dichlorotris(2-aminomethylpyridine)nickel(II) dihydrate is consist by two bands. The strongest band appear in the 200-300 nm region, is primarily due to ligand to ligand charge transfer (LLCT) attributed to transition states of 2-AMP, the absorption band observed at $268 \mathrm{~nm}$ describe the small contribution from metal to ligand charge transfer (MLCT) [16], whereas the reported values in literature are in the range of $200-400 \mathrm{~nm}$ which attributed to ligand to ligand charge transfer (LLCT) with a small contribution from metal to ligand charge transfer (MLCT) [4]. In addition, a weak band appear in the 500-800 $\mathrm{nm}$ region which can be attributed to the $\mathrm{d}-\mathrm{d}$ transitions of metal transition [17]. 


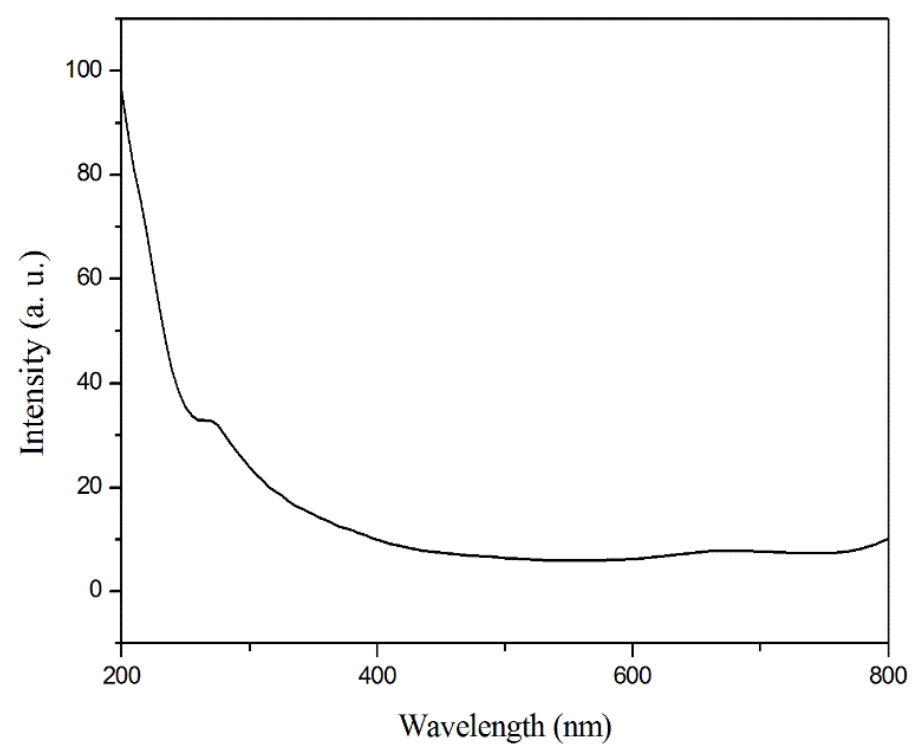

Fig. 11. Diffusion reflectance spectrum of dichlorotris(2-aminomethylpyridine)nickel(II) dihydrate at room temperature.

The band gap energy determination depends on a linear part of the spectrum. This region of high absorption corresponds to the fundamental absorption $(1<300 \mathrm{~nm})$, resulting from the inter band electronic transition. The gap energy can be defined as difference of energy between the lowest conduction band free of electrons and the highest valence band maximum filled with electrons that is related to the electric conductivity of the materials [18]. Using the Kubelka-Munk (K-M) (2) model and the Tauc methods (3) the band gap energy (Eg) of the compound can be determined. The K-M method is expressed by the equation (2) [19,20,21]:

$F\left(R_{d}\right)=\frac{(1-R)^{2}}{2 R_{d}} \quad, \quad F(R)_{d}=\frac{\alpha}{S}$

where: $\quad R_{d}$ : diffuse reflectance of light

a: absorption coefficient of light

S: diffusion coefficient of light

According the theory of Tauc and Abeles the optical band gap was determined using relation (3)

$(\alpha h v)^{x}=A\left(h v-E_{g}\right)^{n}$

$\alpha$ : absorption coefficient

hv: energy of the incident photon

h: Planck's constant (J.s), v: light frequency $\left(\mathrm{s}^{-1}\right)$

A: absorption constant 
Eg: optical gap energy (eV)

$\mathrm{n}$ : a constant that takes different values depending on the type of electronic transition, for an indirect allowed transition $\mathrm{n}$ is equal to 2 , (plotted as $(\mathrm{F}(\mathrm{R}) \mathrm{hv})^{1 / 2}$ versus $\mathrm{E}$ and $\mathrm{n}$ is equal to $1 / 2$ for a direct allowed transition (plotted as $(\mathrm{F}(\mathrm{R}) \mathrm{hu})^{2}$ versus $\mathrm{E}$. The $\mathrm{K}-\mathrm{M}$ method can be used as a standard model to determine the optical gap for organic-inorganic semiconductors [22].

The Eg value was obtained by extrapolating the slope to $(\mathrm{F}(\mathrm{R}) \mathrm{hv})^{n}$ equal to zero. The direct and indirect transitions (Fig. 12) for the compound show a band gap values equal to 1.30 and $1.64 \mathrm{eV}$, respectively. As reported in the literature [26], the lower optical band gap of the material is incredibly significant in applications of electronic and optoelectronic devices.
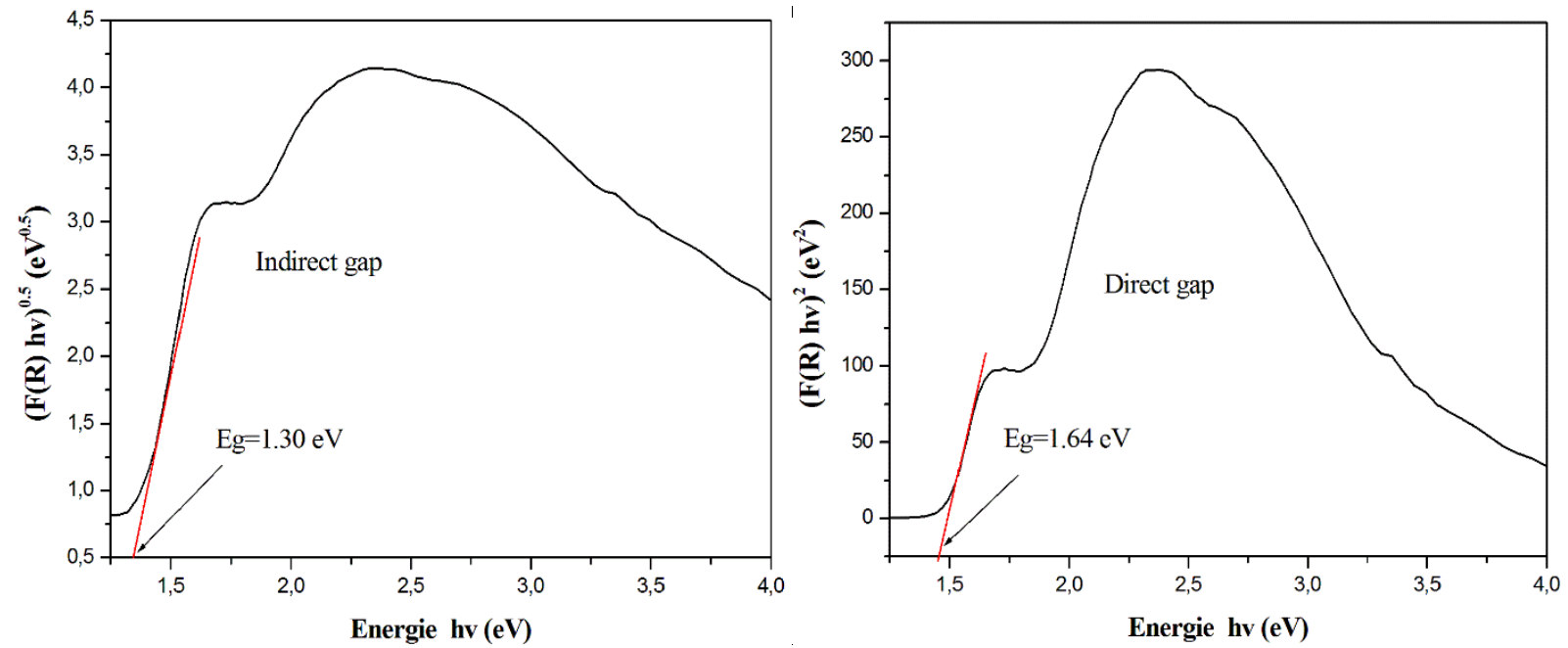

Fig. 12. Tauc Plots of $(F(R) h v)^{1 / 2}$ versus $E(a)$ and $(F(R) h v)^{2}$ versus $E(b)$ of dichlorotris(2aminomethylpyridine)nickel(II) dihydrate.

\section{Conclusion}

In summary, a novel coordination complex $\left[\mathrm{Ni}\left(\mathrm{C}_{6} \mathrm{H}_{8} \mathrm{~N}_{2}\right)_{3}\right] \mathrm{Cl}_{2} .2\left(\mathrm{H}_{2} \mathrm{O}\right)$ formed by nickel with the 2aminopyridine ligand has been successfully synthesized at room temperature by slow evaporation. This compound belongs to the triclinic system with the P-1 space group and characterized through single-crystal X-ray diffraction, IR and UV-Vis diffuse reflectance spectroscopy. The crystal structure of dichlorotris(2-aminomethylpyridine)nickel(II) dihydrate is stabilized by $\mathrm{N}-\mathrm{H} \ldots \mathrm{Cl}, \mathrm{O}-$ $\mathrm{H} . . . \mathrm{Cl}$ and $\mathrm{N}-\mathrm{H} . . . \mathrm{O}$ hydrogen bonds. Moreover, 2-amino-methlpyridine shows a $\pi$ - $\pi$ interaction adding extra stability to the three-dimensional architecture. Vibrational study has been carried out to identify the functional groups present in the crystal and the gap energy values equal to 1.30 and 
$1.64 \mathrm{eV}$ confirmed that this compound can be classified as semiconductor which can be used in electronic and optoelectronic applications.

\section{Acknowledgment:}

The authors extend their appreciation to the Deanship of Scientific Research at King Khalid University for funding this work through General Research Project under grant number (G.R.P235-41). 


\section{References}

${ }^{1}$ A. Nangia, Supramolecular chemistry and crystal engineering., Journal of Chemical Sciences, 2010, $122,295$.

https://doi.org/10.1007/s12039-010-0035-6.

${ }^{2}$ C. P. Pradeep, S. K. Das, Coordination and supramolecular aspects of the metal complexes of chiral Nsalicyl- $\beta$-amino alcohol Schiff base ligands: Towards understanding the roles of weak interactions in their catalytic reactions, Coordination Chemistry Reviews., 2013, 257, 1699.

https://doi.org/10.1016/j.ccr.2013.01.028.

${ }^{3}$ J. P. Yang, H. P. Hu, Z. Y. Cheng, X. J. Qiu, C. X. Wang, Structural insights into the coordination and selective extraction of copper(II) by tertiary amine ligands derived from 2-aminomethylpyridine;

Polyhedron., 2017, 128, 76.

https://doi.org/10.1016/j.poly.2017.02.037.

${ }^{4}$ S. S. Sunkari, B. Kharediya, S. Saha, B. Elrezcd, J. P. Sutter, Chain of dimers to assembly of trimers: temperature and ligand influenced formation of novel supramolecular assemblies of $\mathrm{Cu}$ (II) with isomeric (aminomethyl) pyridines and azide; New Journal of Chemistry., 2014, 38, 3529.

https://doi.org/10.1039/c4nj00374h.

5 B. F. Abbas, B. A. F. Kamel, W. M. Khamais, Preparation, Diagnosis, Biological Activity, and Theoretical Studies of Some Mixed Drug Complexes; The Scientific World Journal., 2019, 7. https://doi.org/10.1155/2019/8962923.

${ }^{6}$ W. Y. Dan, Y. Y. Di, Y. J. Liu, Y. X. Kong, Z. C. Tan, Low-Temperature Heat Capacities and Standard Molar Enthalpy of Formation of Dichloro Bis(2-aminopyridine) Zinc (II), $\mathrm{ZnCl}_{2}\left(\mathrm{C}_{5} \mathrm{H}_{6} \mathrm{~N}_{2}\right)_{2}$ (s)., International Journal of Thermophysics., 2010, 31, 2103. https://doi.org/ 10.1007/s10765-010-0887-5.

${ }^{7}$ M. Okamato, K. Takahashi, T. Doi, Y. Takimoto, Anal. High-sensitivity detection and postsource decay of 2-aminopyridine-derivatized oligosaccharides with matrix-assisted laser desorption/ionization mass spectrometry. Analytical Chemistry., 1997, 69, 2919. https://doi.org/10.1021/ac960910s.

${ }^{8}$ S. D. Bella, A. Colombo, C. Dragonetti, S. Righetto, D. Roberto, Zinc(II) as a Versatile Template for Efficient Dipolar and Octupolar Second-Order Nonlinear Optical Molecular Materials. Inorganics 2018, 6(4), 133. https://doi.org/10.3390/inorganics6040133.

9 H. S. Sun, Y. M. Xu, W. He, S. G. Tang, C, Guo. (Z)-5-(4-Fluoro-benzyl--idene)-1,3-thia-zolidine-2,4dione. Enraf Nonius, CAD4, Solfware, version 5.0, 1989. https://doi.org/10.1107/S1600536807068316.

${ }^{10}$ A. C. T. North, D. C. Phillips, F. S. Mathews, A semi-empirical method of absorption correction, Acta Crystallographica Section A., 1968, A24, 351. https://doi.org/10.1107/S0567739468000707.

${ }^{11}$ K. Brandenburg DIAMOND, Version 3.2e, Crystal Impact GbR, Bonn, Germany, 2007.

${ }^{12}$ A. Parkin, G. Barr, W. Dong, C.J. Gilmore, D. Jayatilaka, J.J. McKinnon, M.A. Spackman, C.C. Wilson, Comparing entire crystal structures: structural genetic fingerprinting. CrystEngComm., 2007, 9, 648. https://doi.org/10.1039/B704177B. 
${ }^{13}$ M. A. Spackman, J. J. McKinnon, Fingerprinting intermolecular interactions in molecular crystals. CrystEngComm., 2002, 4, 378. https://doi.org/10.1039/B203191B.

${ }^{14}$ H. Wang, H. Xiao, N. Liu, B. Zhang, Q. Shi, Three New Compounds Derived from Nitrofurantoin: XRay Structures and Hirshfeld Surface Analyses. Journal of Inorganic Chemistry., 2015, 5, 10. https://doi.org/10.4236/ojic.2015.53008.

${ }^{15}$ H. Chebbi, S. mezrigui, M. B. Jomaa, M. F. Zid, Crystal structure, Hirshfeld surface analysis and energy framework calculation of the first oxoanion salt containing 1,3-cyclohexanebis(methylammonium), Acta $\begin{array}{lllll}\text { Crystallographica } & \text { Section } & \text { E., } & \text { 2018, } & \text { E74, }\end{array}$ https://doi.org/10.1107/S2056989018008381.

${ }^{16}$ W. Amamou, N. Chniba-Boudjada, F. Zouari, Crystal structure, vibrational and magnetic properties of the monohydrated cobalt (II) complex with 1-(4-Nitrophenyl)-1Himidazolium cation, $\left(\mathrm{C}_{9} \mathrm{H}_{8} \mathrm{~N}_{3} \mathrm{O}_{2}\right) 2 \mathrm{CoCl}_{4} \cdot \mathrm{H}_{2} \mathrm{O}$, Journal of Molecular Structure., 2017, 1127, 266.

https://doi: 10.1016/j.molstruc.2016.07.111.

${ }^{17}$ S. S. Sunkari, B. Kharediya, S. Saha, B. Elrez, J. P. Sutter, Chain of dimers to assembly of trimers: temperature and ligand influenced formation of novel supramolecular assemblies of $\mathrm{Cu}$ (II) with isomeric (aminomethyl) pyridines and azide, New Journal of Chemistry., 2014, 38, 3529. https://doi.org/10.1039/C4NJ00374H.

${ }^{18}$ H. Hashim, M. Abdallh, E. Yousif, Studying the influence of cobalt chloride on the optical properties of poly (vinyl alcohol) films, Journal Al-Nahrain University., 2012, 15, 40.

${ }^{19}$ P. Kubelka, F. Munk, Z. Ion exchange recovery of palladium (II) from nitrate weak acidic solutions Tech. Phys., 1931, 12, 593.

${ }^{20}$ S. Hassen, H. Chebbi, M.F. Zid, Y. Arfaoui. Crystal structure, spectroscopic study, photoluminescent properties and DFT calculations of the 2-guanidinobenzimidazolium dichloride and dibromide monohydrate salts. Journal of Molecular Structure., 2018, 1167, 1. https://doi.org/10.1016/j.molstruc.2018.04.073.

${ }^{21}$ O. B. Moussa, H. Chebbi, Y. Arfaoui, L.R. Falvello, M. Tomas, M.F. Zid, Structural study, vibrational and optical properties, Hirshfeld surface analysis and DFT investigation of a novel organic cation hexachloridostannate(IV), $\left(\mathrm{C}_{5} \mathrm{H}_{8} \mathrm{~N}_{3}\right)_{2}\left[\mathrm{SnCl}_{6}\right]$, Journal of Molecular Structure., 2019, 1159, 344. https://doi.org/10.1016/j.molstruc.2019.05.066.

${ }^{22}$ W. Selmi, J. Abdelhak, M. Marchivie, M. F. Zid, A comparative structural, spectroscopic, optical and photoluminescence studies by DFT of Fe(II) difluoro(oxalato)borate complex. Journal of Photochemistry and Photobiology A: Chemistry., 2018, 352, 43.

https://doi.org/10.1016/j.jphotochem.2017.10.029.

${ }^{26}$ N. F. Mott, E. A. Davis, Electronic process in non-crystalline materials. Oxford: Calendron Press., 1979. 